\title{
Effect of Tools Geometry and Dwell Time on Mechanical Properties and Macrograph of Two-Stage Refilled Friction Stir Spot Micro Weld
}

\author{
Ario Sunar Baskoro, ${ }^{1, *}$, Mohammad Azwar Amat ${ }^{1}$ and Muhammad Andre Widiyanto ${ }^{1}$ \\ ${ }^{1}$ Department of Mechanical Engineering, University of Indonesia, West Java, Indonesia
}

\begin{abstract}
In this present study, the two independent tools were used in the RFSSW process to joint similar material of AA1 100 with a thickness of $0.42 \mathrm{~mm}$ using lap joint configuration. Effect of tools geometry and dwell time on mechanical properties, and macrograph was investigated. The joints were successfully obtained with better surface appearance. The micro-hardness variation at 4 group location shows higher than the base metal, while the maximum micro-hardness was obtained at parameter TC- 8 at the center of the weld. Macrograph analysis showed the important factor that brings the plug fracture in all combination of parameters. It was the upward bending hook that leads to the crack propagate along the stirred zone to the top sheet, resulted in tear-off the top sheet from the bounded region. Increasing dwell time and tools size will increase the maximum tensile shear load significantly. The best average value of maximum tensile shear load that has been achieved was $561 \pm 24 \mathrm{~N}$ using the parameter tool $\mathrm{C}$ with $8 \mathrm{~s}$ dwell time (TC-8).
\end{abstract}

\section{Introduction}

Friction stir welding (FSW) is widely and very popular for joining aluminum alloys and has many advantages from other conventional welding processes such as resistance spot welding (RSW) or fusion welding such as TIG/MIG [1]. Friction stir welding was invented by the TWI in 1991. It can be implemented such in aluminum, copper, magnesium, titanium, zinc, even steel [2],[3]. Currently, FSW has derived another technique namely friction stir spot welding (FSSW). The process that involving FSSW almost the same as FSW, but only at one spot during the process. However, after the FSSW process done, the joining left a keyhole that can be a problem here after (i.e. corrosion, fatigue life) and reduce the capability of the joint strength potential. So, a technique called refill friction stir spot weld introduced and developed by GKSS GmbH [4] in 2004. RFSSW involves two stages which are plunge stage and refill stage. Many researchers used one compact tool that involves those two stages [4]-[10]. While the other uses two independent tools [11].

The previous study has been reported that the major contribution to the strength of RFSSW is in the stirred zone (SZ) area [7], while others state it was related to size and morphology of hook defect [4],[12]. Therefore, it can be presumed that the strength mainly depends on the macro and microstructure feature. The process condition itself has a correlation to the macro and microstructure on the SZ area and the morphology of the hook defect. Rotational speed, plunge rate, plunge depth, dwell time and joining time have correlated to the mechanical strength. Microstructure and mechanical properties have become the main focus of the study in many researchers [1],[4],[7]-[10],[13]-[15]. While others focused on the failure mechanism [5], joint morphology [12], thermal investigation and material flow [16]. Tools geometry are the most important to be considered. Directly, the tools geometry contribute significantly to the tensile strength [17],[18].

$\mathrm{Li}$ et al. [12] used probless pin for friction stir spot weld (P-FSSW). They studied the joint morphology and the microstructure of P-FSSW using $1.8 \mathrm{~mm}$ sheets of AA2198. Garg and Bhattacharya [17] investigated the influence of different tools and pin geometries in similar and dissimilar material. They studied the strength and failure mechanism of a combination of AA6061 and pure $\mathrm{Cu} 0.5 \mathrm{~mm}$ thick sheets. Zarghani et al. [15] introduced the protrusion on back plate and used pinless tool for joining similar material $1 \mathrm{~mm}$ thick of AA2024. This implemented technique can reduce the keyhole after FSSW process. Reimann et al. [6] introduced new approach that implemented cylindrical plug (i.e. filler) of the same material into the keyholes. Afterward, the RFSSW process was used to join the filler with the surrounding material. However, this technique was implemented in $4.8 \mathrm{~mm}$ of AA6061, relatively thick material. Sajed [11] used two independent tools for RFSSW and applied into $2 \mathrm{~mm}$ thick aluminum 1100 alloys. Wang et al. [19] investigated mechanical properties and microstructure of micro friction stir spot weld ( $\mu$ FSSW) using $300 \mu \mathrm{m}$ sheets of AA1050. 
Table 1. Mechanical and thermal properties of the 1100 alloy $-\mathrm{H} 16$ (at $25^{\circ} \mathrm{C}$ )

\begin{tabular}{ccccccc}
\hline $\begin{array}{c}\text { Yield strength } \\
(\mathrm{MPa})\end{array}$ & $\begin{array}{c}\text { Tensile } \\
\text { strength } \\
(\mathrm{MPa})\end{array}$ & $\begin{array}{c}\text { Elongation } \\
(\%)\end{array}$ & $\begin{array}{c}\text { Hardness } \\
(\mathrm{HV})\end{array}$ & $\begin{array}{c}\text { Thermal } \\
\text { conductivity } \\
\left(\mathrm{W} \cdot \mathrm{m}^{-1} \cdot \mathrm{K}^{-1}\right)\end{array}$ & $\begin{array}{c}\text { Heat capacity } \\
\left(\mathrm{J}_{\mathrm{kg}}^{-1} \cdot \mathrm{K}^{-1}\right)\end{array}$ & $\begin{array}{c}\text { Melting point } \\
\left({ }^{\circ} \mathrm{C}\right)\end{array}$ \\
\hline 130 & 150 & 8 & 38 & 220 & 904 & $643-657$ \\
\hline
\end{tabular}

Table 2. The chemical composition of the 1100 alloy used in this study (wt $\%$ ).

\begin{tabular}{cccccccc}
\hline $\mathrm{Al}$ & $\mathrm{Cu}$ & $\mathrm{Mn}$ & $\mathrm{Mg}$ & $\mathrm{Si}$ & $\mathrm{Fe}$ & $\mathrm{Zn}$ & Other \\
\hline$>99.0$ & $0.1-0.2$ & $0.02-0.05$ & $0.03-0.05$ & $0.15-0.20$ & $0.25-0.4$ & $0.05-0.1$ & 0.1 \\
\hline
\end{tabular}
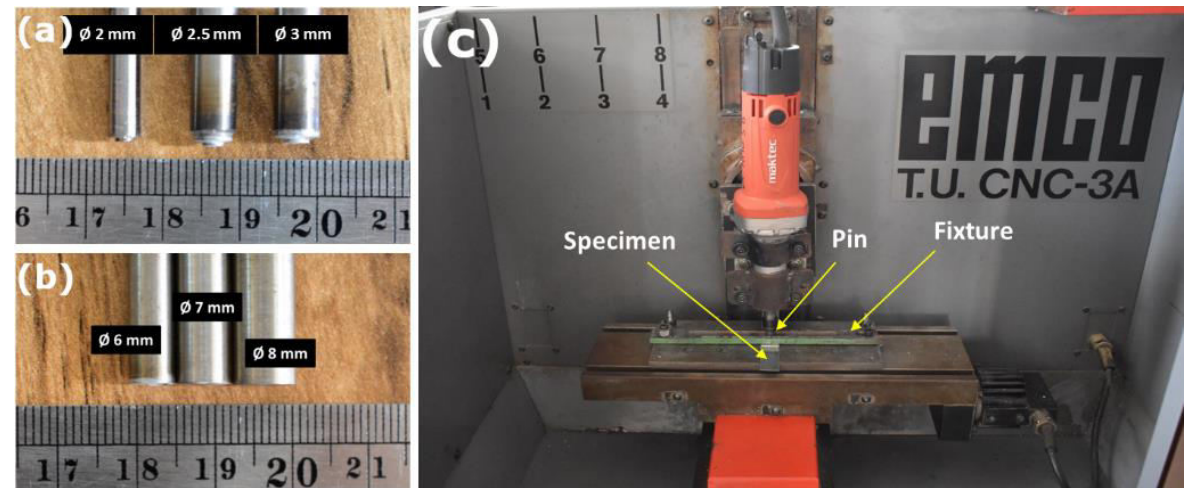

Fig. 1 (a) indpendent tool first stage (b) indpendent tool second stage (c) RFSSW schematic setup

In the current work, two-stage RFSSW is used to join thin sheets of AA1100 with $0.42 \mathrm{~mm}$ thickness. RFSSW was performed by using two independent tools. The basic concept is simple, after the plunge stage (1st stage), the refill stage (2nd stage) used the larger flat pin diameter compared to the first one. The effect of tool pin and dwell time on microstructure feature and mechanical properties was investigated in detail.

\section{Experiments}

1100 aluminum alloy of $0.42 \mathrm{~mm}$ thickness was used to produce overlap joints configuration using RFSSW with two independent tools. The specimens was cut into $150 \times 20 \mathrm{~mm}^{2}$ and the overlap area was $30 \times 20 \mathrm{~mm}^{2}$. Table 1 shows the mechanical and thermal properties of AA1100-H16, while Table 2 shows the chemical composition of base metal. The combination of the first and the second independent tools was named tool $\mathrm{A}$, tool $\mathrm{B}$, and tool C. The first independent tool for tool A, B, and $\mathrm{C}$ have a combination of pin/shoulder diameter were $2 / 4 \mathrm{~mm}, 2.5 / 5 \mathrm{~mm}$ and $3 / 6 \mathrm{~mm}$, respectively. The shoulder diameter was two times of pin diameter and the height of the pin was $0.6 \mathrm{~mm}$ (Fig. 1a). For the second tool used a flat pin with diameter of $6 \mathrm{~mm}, 7 \mathrm{~mm}$ and 8 $\mathrm{mm}$ (Fig. 1b). Therefore, the combination tools geometry was used in this study were 2-4-6 (tool A), 2.5-5-7 (tool B), 3-6-8 (tool C). The conventional method of FSSW (without the second stage) was presented for comparative macrograph analysis to the RFSSW. As shown in Fig. 1c, the weld was performed using CNC milling which has been modified with a grinding machine attached to that. The machine has a capacity of 480 watts at full load. Without any load, the machine could reach a maximum rotational speed of 33,000 RPM. In the welding process, there were two dwell times, the first dwell time at the first stage was set constant $8 \mathrm{~s}$ in all condition parameters and the second dwell time at the second stage was varying to $4 \mathrm{~s}, 6 \mathrm{~s}$ and $8 \mathrm{~s}$. Plunge rate and plunge depth were set constant at $2 \mathrm{~mm} / \mathrm{min}$ and 0.6 $\mathrm{mm}$, respectively.

Four samples were taken in each combination types of tool and the second stage dwell time. There were 9 combinations for the tensile shear test. Standard universal tensile testing machine TENSILON $50 \mathrm{kN}$ was used to measure the tensile shear load of the joint. As shown in Table 3, for macrograph and hook geometry studies 9 samples with 3 of them were samples of conventional FSSW. Material preparation used standard metallography procedure with $0.5 \% \mathrm{HF}$ etched. An Oxion Inverso light optical microscope (OM) used to observe the microstructural and the hook morphology. The micro-hardness distribution was taken after the observation macro and microstructural. Micro-hardness measurement used a load of $25 \mathrm{gf}$ and $15 \mathrm{~s}$ dwell time, the micro-hardness distribution group spots is shown in Fig. 2.

\section{Results}

\section{Surface appearance}

The surface appearance from the top view of typical conventional FSSW joints (Fig. 3a, c, and e) and a typical two-stage refill FSSW joints (Fig. 3b, d and f) with the different type of tools. From Dino-lite observation, 

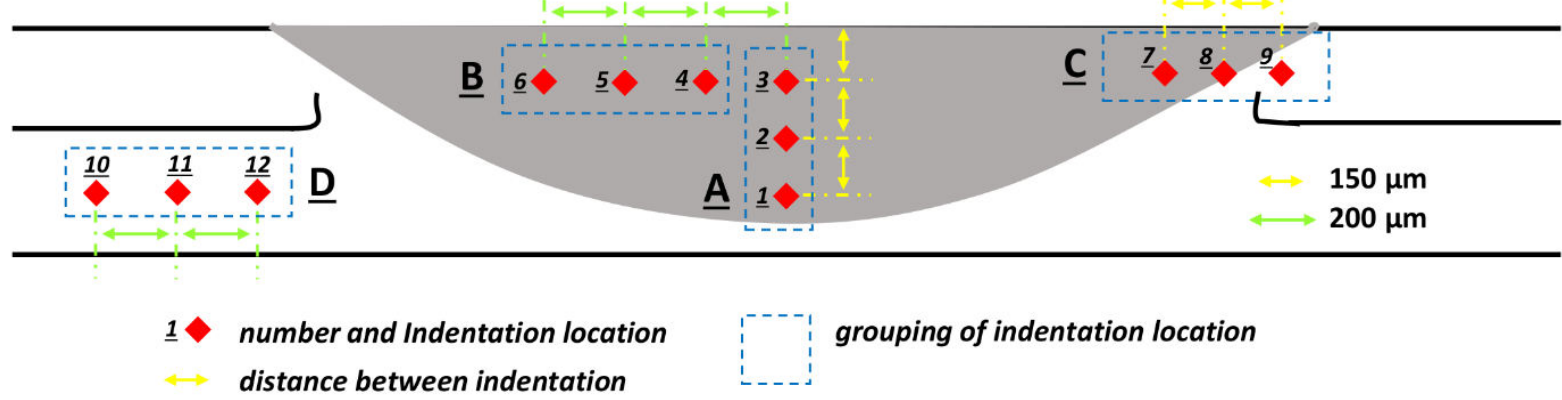

Fig. 2 Micro-hardness location measurement
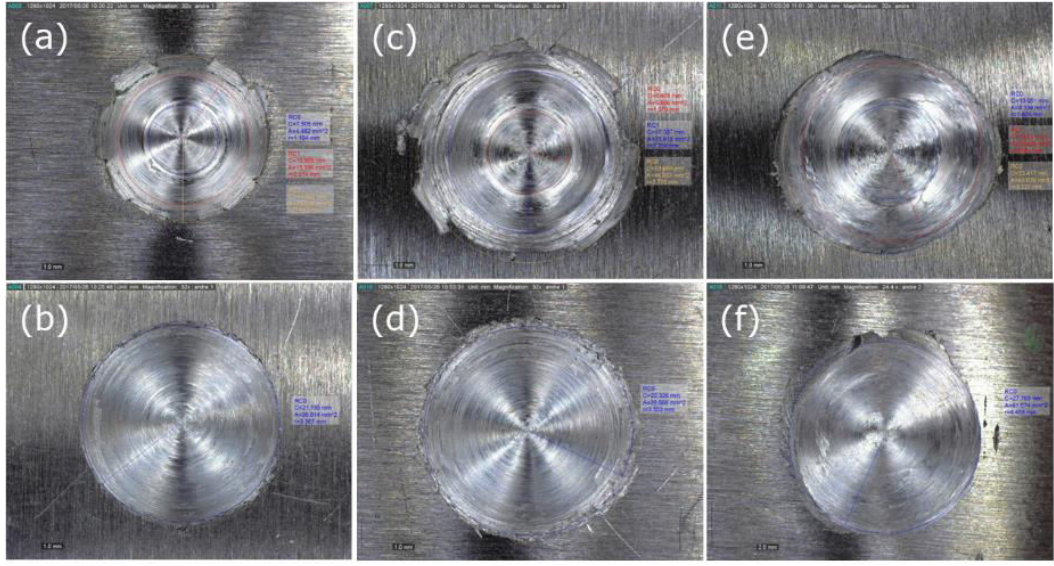

Fig. 3 Top view of conventional FSSW and RFSSW using (a-b) tool A (c-d) tool B (e-f) tool C, all condition using dwell time $6 \mathrm{~s}$

it is clearly shown better appearance compared to the conventional FSSW. Keyhole was completely closure after the $2^{\text {nd }}$ stage refilling process. The typical appearance surface was observed in all welding conditions.

\subsection{Macro and microstructure}

Fig. 4 show the cross-sectional macrograph of the sample produced by tool $\mathrm{A}$ at dwell time $4 \mathrm{~s}$ and $8 \mathrm{~s}$. Fig. 4a shows the macrostructure of conventional FSSW with a combination of pin and shoulder diameter of $2 \mathrm{~mm}$ and $4 \mathrm{~mm}$, respectively. During the FSSW process, the plasticized material pushed into the gap between the top and bottom sheets, this creates distortion and space that called upward bulging. This could happen when there was a lack of shoulder indentation and small shoulder size to press, consequence in lack of restraint the material flow into the overlapped sheets. Fig. 4b shows the samples that were welded with $4 \mathrm{~s}$ dwell time. The partial bounded was arrested between the top and bottom sheets. It can be seen in Fig. 4c the stirred zone (SZ) area was better welded due to a longer stirring time. It showed a material flow from the top sheet to the keyhole. However, longer stirring time was not guaranteed to be a void free. As can be seen in Fig. 4c incomplete refill does occur in the bottom sheet.
Table 3. Measurement and data collection

\begin{tabular}{|c|c|c|c|}
\hline \multirow{2}{*}{$\begin{array}{c}\text { Dwell } \\
\text { time (s) }\end{array}$} & \multicolumn{3}{|c|}{ Tools type } \\
\hline & A & B & C \\
\hline 4 & $0^{\circ}$ & 0 & - \\
\hline 6 & $\bullet$ & 80 & 0 \\
\hline 8 & 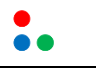 & • & 00 \\
\hline $\begin{array}{l}\text { tensile } \\
\text { micros }\end{array}$ & $\begin{array}{l}\text { st } \\
\text { servation }\end{array}$ & $\begin{array}{l}\text { micro-hardn } \\
\text { dino-lite pho }\end{array}$ & \\
\hline
\end{tabular}

Table 4. Joint length of the RFSSW at various parameter

\begin{tabular}{|c|c|}
\hline Parameter & Joint length \\
\hline $2 \mathrm{~mm}-4 \mathrm{~s}$ & $2.2 \mathrm{~mm}$ \\
\hline $2 \mathrm{~mm}-8 \mathrm{~s}$ & $3.2 \mathrm{~mm}$ \\
\hline $2.5 \mathrm{~mm}-4 \mathrm{~s}$ & $4.2 \mathrm{~mm}$ \\
\hline $2.5 \mathrm{~mm}-6 \mathrm{~s}$ & $4.1 \mathrm{~mm}$ \\
\hline $3 \mathrm{~mm}-6 \mathrm{~s}$ & $4.7 \mathrm{~mm}$ \\
\hline $3 \mathrm{~mm}-8 \mathrm{~s}$ & $4.7 \mathrm{~mm}$ \\
\hline
\end{tabular}




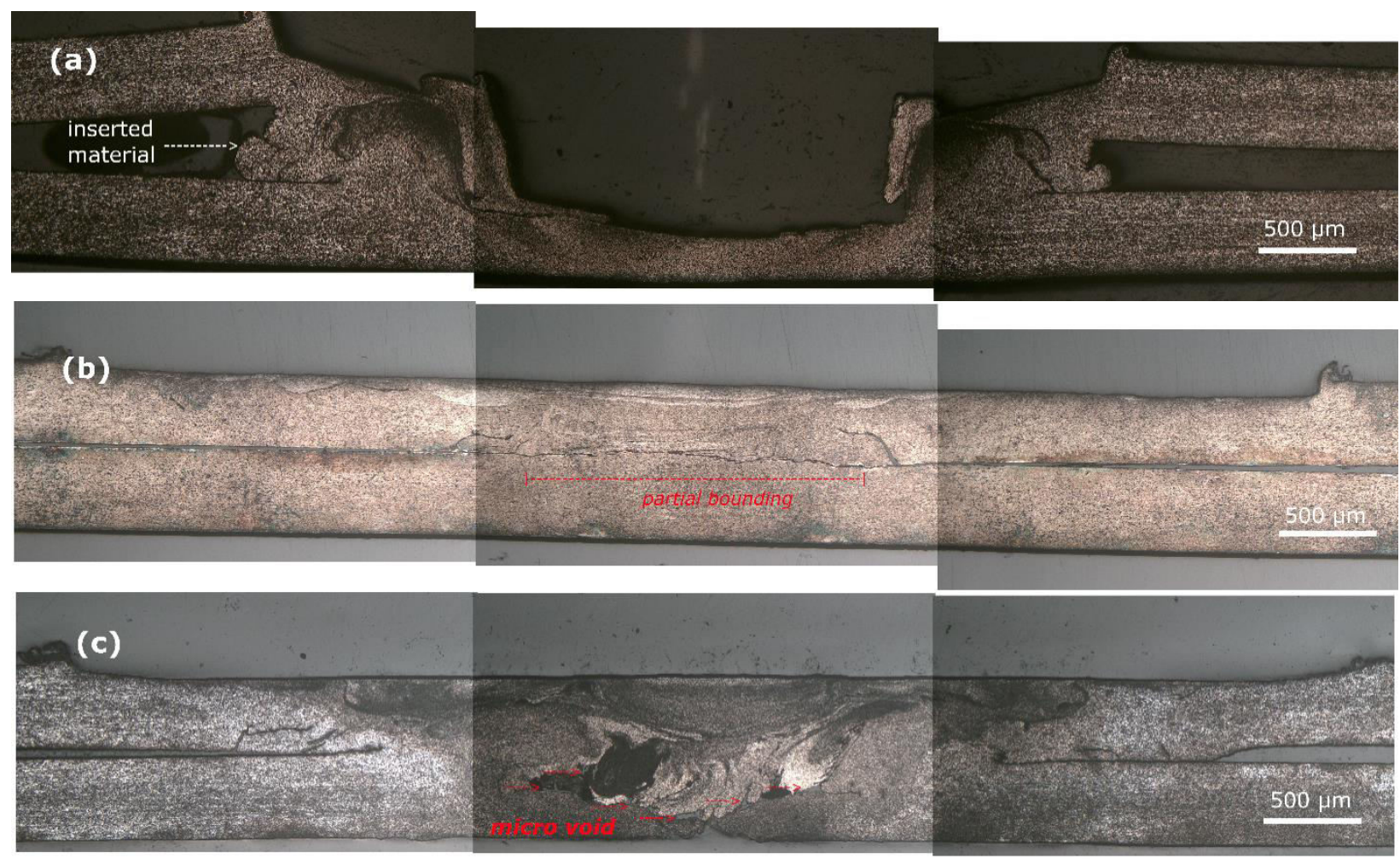

Fig. 4 Pin diameter $2 \mathrm{~mm}$ (a) without $2^{\text {nd }}$ stage (b) dwell time $4 \mathrm{~s}$ (c) dwell time $8 \mathrm{~s}$
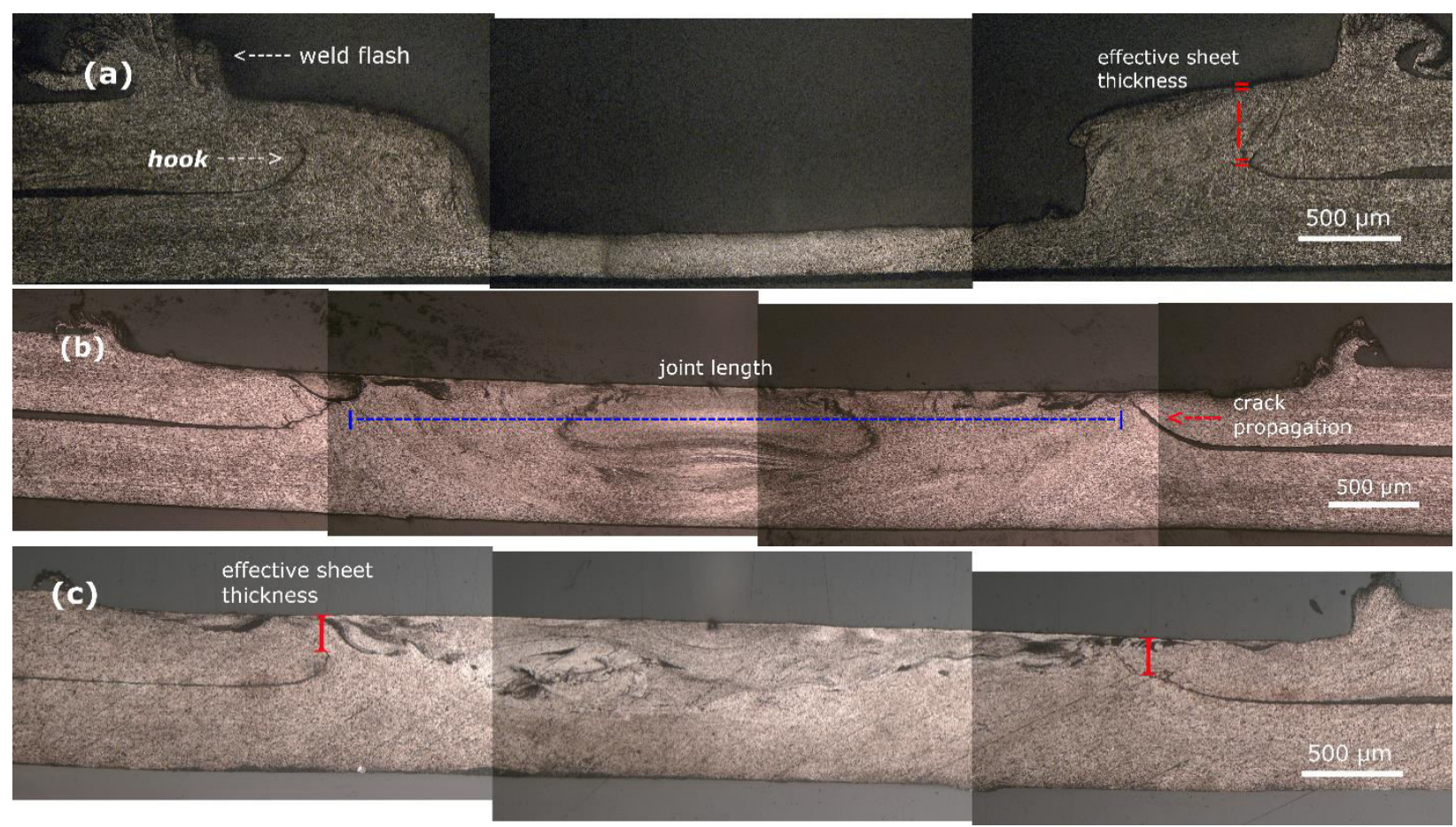

Fig. 5 Pin diameter $2.5 \mathrm{~mm}$ (a) without $2^{\text {nd }}$ stage (b) dwell time $4 \mathrm{~s}$ (c) dwell time $6 \mathrm{~s}$ 

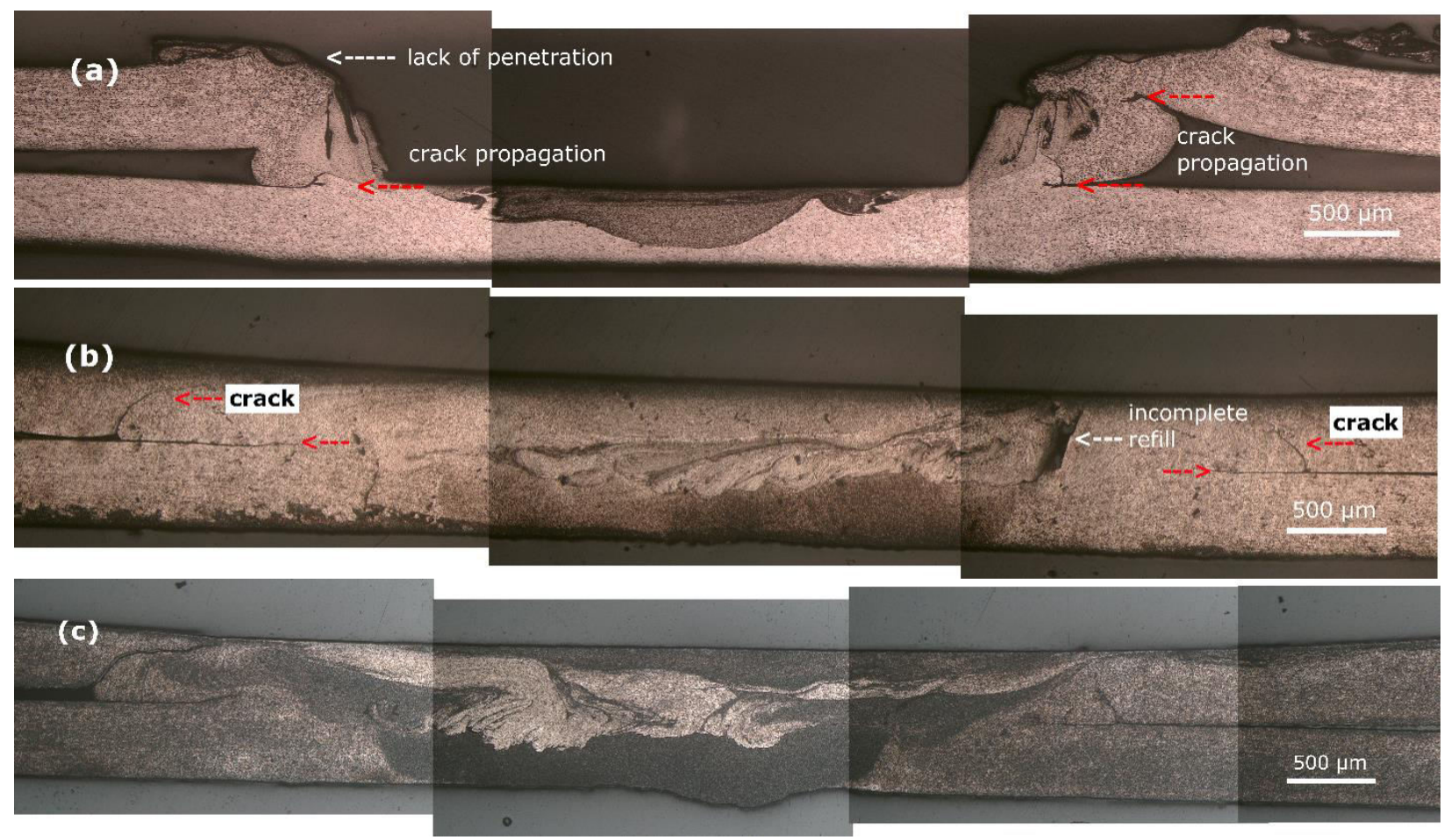

Fig. 6 Pin diameter $3 \mathrm{~mm}$ (a) without $2^{\text {nd }}$ stage (b) dwell time $6 \mathrm{~s}$ (c) dwell time $8 \mathrm{~s}$

Fig. 5 show the cross-sectional macrograph of the sample produced by tool B at dwell time $4 \mathrm{~s}$ and $6 \mathrm{~s}$. Fig. 5 a shows the macrostructure of conventional FSSW with a pin diameter of $2.5 \mathrm{~mm}$ and shoulder diameter of 5 $\mathrm{mm}$. In this process, shoulder size was larger compared to the tool $\mathrm{B}$ and shoulder indentation was enough to push top sheet, therefore restrained the material from flowing into the overlapped sheets. Thus, this would minimalize distortion and space between the overlapped sheets. Fig. 5b shows the joint length that has a correlation to the joint strength, the joint length of 6 samples were shown in Table 4. Size of tools geometry has direct influence to the joint length, while the dwell time has not influenced the joint length. Fig. 5c shows the effective sheet thickness, this depends on the height of the hook. Fig. 6 show the cross-sectional macrograph of the sample produced by tool $\mathrm{C}$ at dwell time $6 \mathrm{~s}$ and 8 s. Fig. 6a shows the macrostructure of conventional FSSW with a combination of pin and shoulder diameter of $3 \mathrm{~mm}$ and $6 \mathrm{~mm}$ respectively. The plasticized material was inserted into overlapped sheets because of the lack of shoulder penetration. Incomplete refill was arrested in Fig. $6 \mathrm{~b}$ and showed a branch of crack propagation. Branch crack has an associated to the tools geometry selected, large size will tend to raise the branch crack. As shown in Fig. 7 the SZ was characterized by very fine equiaxed grains with a size of particles less than $5 \mu \mathrm{m}$. This microstructure was endured a high strain rate and long thermal cycle during the process. This leads to an imposed intense plastic deformation while in high temperature, then resulted in dynamic recrystallization. Fig. $7 \mathrm{a}$ and $7 \mathrm{~b}$ show two distinct regions in SZ, white and black region. The black region was characterized by granular microstructure which covers all area (Fig. 7d), whereas in the white region contain some granular that spread randomly (Fig. 7c).

\subsection{Micro-hardness}

Fig. 2 shows a micro-hardness distribution that divided into four grouped regions namely, group A, B, $\mathrm{C}$, and D. Each group contain 3 indentations, total 12 indentations. Each indentation was namely location 1-12 at group A (1-3), group B (4-6), group C (7-9) and group D (10-12). Group A represents of vertical microhardness at the center of the weld, the indenters were spacing $150 \mu \mathrm{m}$ at each location from the edge of the top stirred area. Group B represents of horizontal microhardness from the center of the weld to the left side, the indenters were spacing $200 \mu \mathrm{m}$ at each location from the center of the weld and it is parallel to indenters number 3. Group C represents of micro-hardness at SZ boundary, the indenters were spacing $150 \mu \mathrm{m}$, it was expected this region might be TMAZ area. Group D represents the base metal (BM) that has been slightly affected by heat and compressive force. Three samples were elected to show the effect of the tools geometry and the dwell time to the hardness variation. Tool A with $4 \mathrm{~s}$ dwell time (TA-4), tool B with $6 \mathrm{~s}$ dwell time (TB-6) and tool C with $8 \mathrm{~s}$ dwell time (TC-8).

Fig. 8 shows the result of micro-hardness variation, at group A, TC-8 has a consistent result of microhardness variation at $82.1 \mathrm{HV}$ while the others have a significant increase in hardness from bottom to top. The consistent result at the peak hardness in TC- 8 can be attributed to completely refilling process, large compressive force concentrated in the center of the weld 

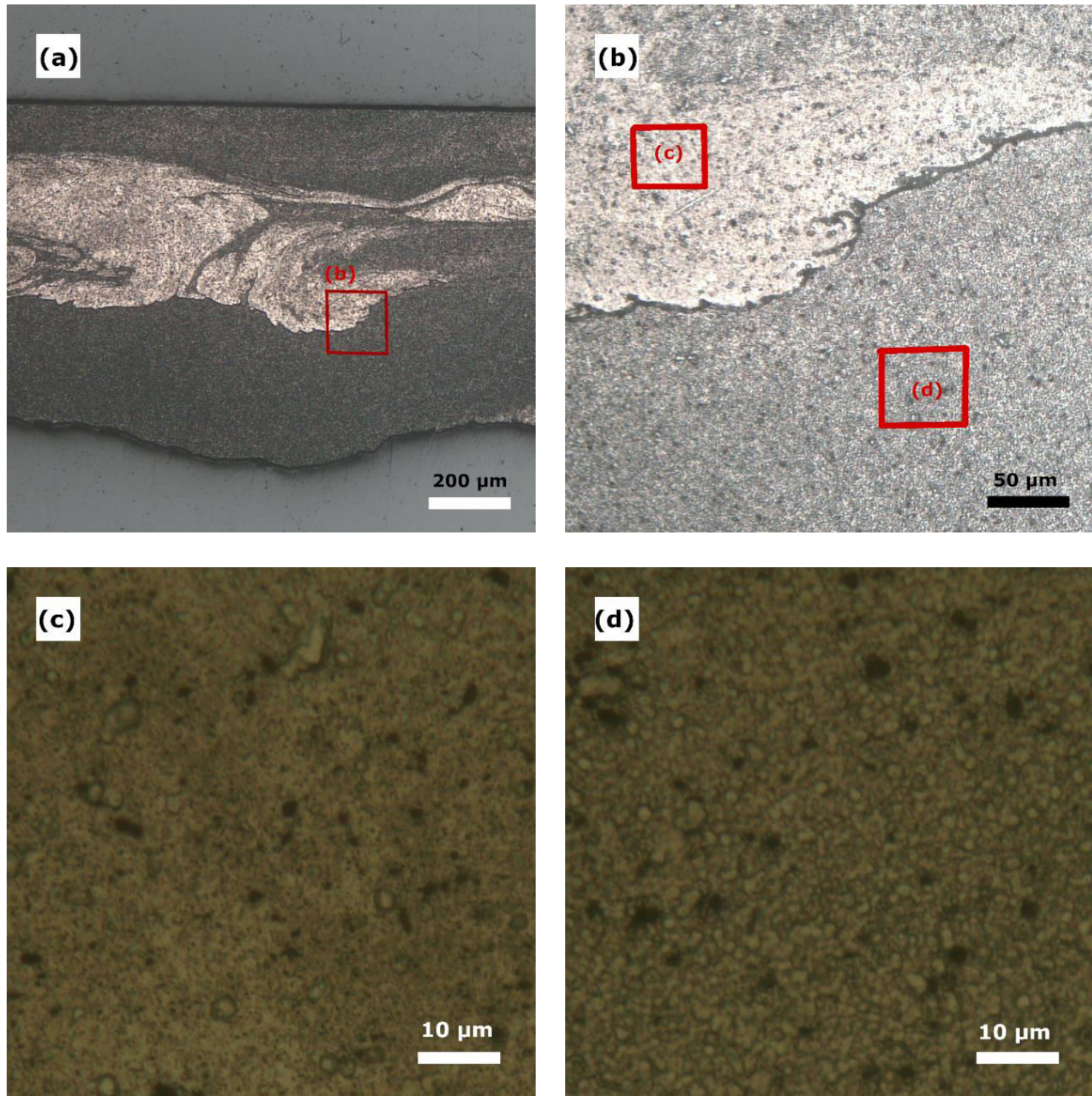

Fig. 7 Microstructure in stirred zone (SZ) area with tool's type C and dwell time $8 \mathrm{~s}$

and longer thermal cycle, consequences in highly compressive stirred zone material, very fine grain size and free defect from voids or pores. Therefore, the SZ area from bottom to top experienced the consistent highstress concentration. Whereas others condition shows a similar trend, increasing hardness from bottom to top. TB-6 has the higher result of hardness compared to TA4. Might be attributed to larger geometry and longer dwell time. At group B, TA-4 has an average value (number 4-6) $57 \mathrm{HV}$, a nearly similar value to the location number 3 (52.6 HV), just one spike value reached $75.6 \mathrm{HV}$ and the others have $46.2 \mathrm{HV}$ and 49.2 HV respectively for number 4 and 6 . TB- 6 has a consistent result from number 3 to 6 and the average value is $59.3 \mathrm{HV}$. TC-8 has decreased hardness value from $82.1 \mathrm{HV}$ to $60.3 \mathrm{HV}$.

It can be concluded that at the center of the weld TC8 has very high local stress concentration, but it decreases when it further away from the center to a value nearly the same as TB-6. At group C, TA-4 has a consistent value of $38.6 \mathrm{HV}$ which is similar to the BM hardness value. TB-6 showed slightly higher than TA-4, it has an average value of $41.8 \mathrm{HV}$. The higher value was achieved at TC-8, the average value of $68.3 \mathrm{HV}$ was similar to the hardness value from group B. This boundary area might be still affected by high compressive stress. At group D, TA-4 has an average value of $47.2 \mathrm{HV}$, nearly the same value at number 4 and 6. TB- 6 and TC- 8 have an average value of 40.3 and $38.0 \mathrm{HV}$ respectively. Both have similar value to the hardness of base metal.

\subsection{Tensile shear load}

Fig. 9 shows the effect of dwell time in each category of pin. The maximum load analysis revealed that dwell time and tools geometry are the important parameters affecting the joint strength. The maximum load increased while dwell time increase in all tool's type. Increasing in dwell time results in increasing the bonding area which is stirred zone (SZ) area. Longer $2^{\text {nd }}$ stage dwell time will have more time to stir material during the refill process. Within high strain rate and the longer thermal cycle will results in finer grain size, 


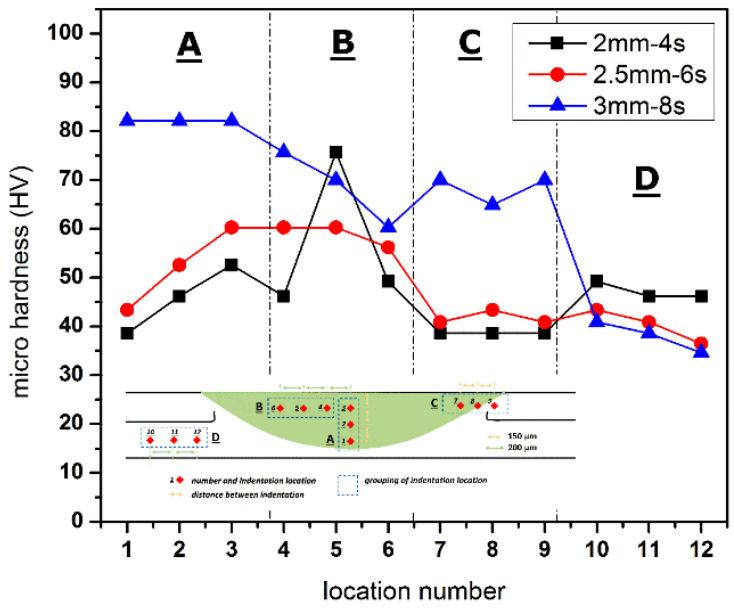

Fig. 8 Hardness variations in some grouped region

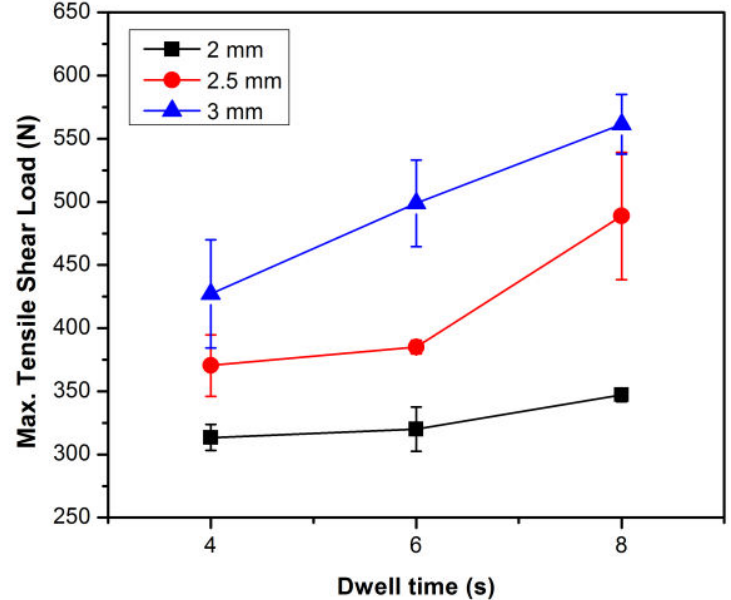

Fig. 9 Maximum tensile shear load vs Dwell time
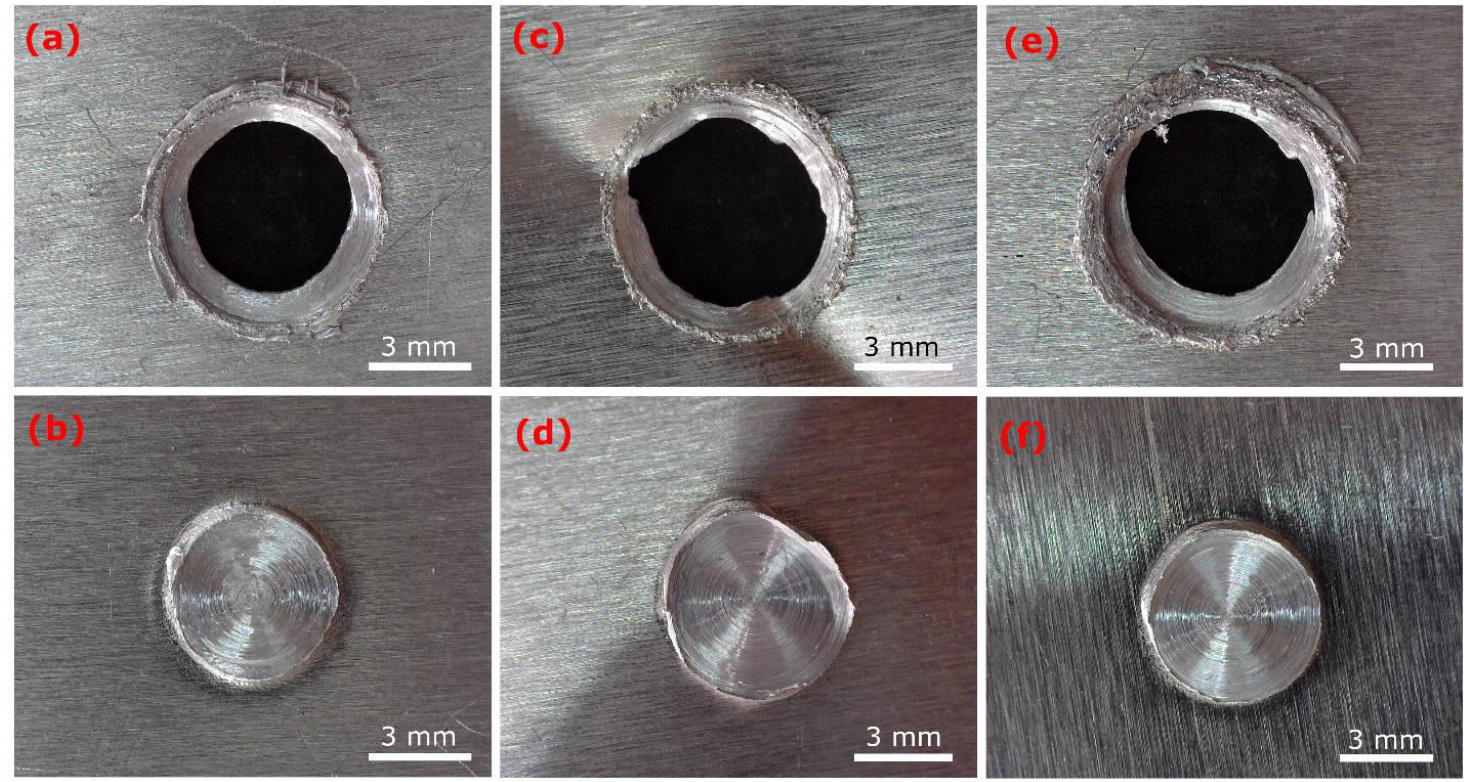

Fig. 10 Fracture modes of RFSSW using (a-b) tool A (c-d) tool B (e-f) tool C, all condition using dwell time $8 \mathrm{~s}$

better filling the keyhole and minimize the potential to incomplete refill or presence of a large void. Larger tools geometry influences of larger joint length at the SZ area. Hence, the maximum load was increased while tools geometry increase. Dwell time has significant contributions on maximum tensile shear load at tool B and tool $\mathrm{C}$, while on tool A dwell time has slightly contributed to maximum load. The experimental result obtained the highest maximum tensile shear load was $347 \pm 5 \mathrm{~N}$ at TA-8, $489 \pm 50 \mathrm{~N}$ at TB-8 and $561 \pm 24 \mathrm{~N}$ at TC-8.

\subsection{Failure mode}

The characteristic of failure mode almost similar in all parameters of tools geometry or dwell time. Only one fracture mode was observed for type tool A, B and C, a failure fracture of the weld are shown in Fig. 10. Plug fracture was observed in all condition of joints. This was caused by the tear-off along the circumference of the joint length at stirred zone area on the top sheet and leaving the bounded region stuck over the bottom sheet, it corresponds to the report by Saju and Narayanan [20]. This mode of failure happens mainly due to the upward bending crack that initial crack propagation to the top sheet.

\section{Conclusion}

In this paper, the effects of tools geometry and dwell time on the mechanical properties and macrograph of the RFSSW joint were analyzed. The main conclusions are listed below: 
1. Two independent tools are shown a promising technique for the micro weld. The appearance has better finishes using RFSSW.

2. Longer dwell time has better welded in SZ area. Varies of tools geometry has direct influence to the joint length, while the dwell time has not influenced the joint length. The SZ area has grain size particles with less than $5 \mu \mathrm{m}$.

3. Micro-hardness revealed that TC- 8 has high-stress concentration in the center of the weld due to highly compressive stirred zone material and very fine grain size. It can be concluded the micro-hardness in SZ approximately around $60 \mathrm{HV}$ at the top edge and reduces to nearly the same as base metal as it goes downward.

4. Dwell time and tools geometry was significantly affected the maximum tensile shear load. Tensile shear load reaches $561 \mathrm{~N}$ at TC-8.

5. The characteristic of failure mode was plug fracture in all condition of joints.

\section{References}

1. T. Rosendo, B. Parra, M.A.D. Tier, A.A.M. da Silva, J.F. dos Santos, T.R. Strohaecker, N.G. Alcântara, Materials \& Design 32, 1094-1100 (2011).

2. W.M. Thomas, D.G. Staines, I.M. Norris, R. De Frias, Welding in the World 47, 10-17 (2003).

3. R.S. Mishra, Z.Y. Ma, Materials Science and Engineering: R: Reports 50, 1-78 (2005).

4. J.Y. Cao, M. Wang, L. Kong, H.X. Zhao, P. Chai, Materials Characterization 128, 54-62 (2017).

5. A. Kubit, M. Bucior, D. Wydrzyński, T. Trzepieciński, M. Pytel, International Journal of Advanced Manufacturing Technology 94, 4479-4491 (2017).

6. M. Reimann, T. Gartner, U. Suhuddin, J. Göbel, J.F. dos Santos, Journal of Materials Processing Technology 237, 12-18 (2016).

7. M.D. Tier, T.S. Rosendo, J.F. dos Santos, N. Huber, J.A. Mazzaferro, C.P. Mazzaferro, T.R. Strohaecker, Journal of Materials Processing Technology 213, 997-1005 (2013).

8. A. Kubit, R. Kluz, T. Trzepieciński, D. Wydrzyński, W. Bochnowski, Archives of Civil and Mechanical Engineering 18, 235-244 (2018).

9. L. Zhou, L.Y. Luo, T.P. Zhang, W.X. He, Y.X. Huang, J.C. Feng, International Journal of Advanced Manufacturing Technology 92, 3425-3433 (2017).

10. M. Reimann, J. Goebel, J.F. dos Santos, Materials \& Design 132, 283-294 (2017).

11. M. Sajed, Journal of Manufacturing Processes 24, 307-317 (2016).

12. W.Y. Li, Q. Chu, X.W. Yang, J.J. Shen, A. Vairis, W.B. Wang, Journal of Materials Processing Technology 252, 69-80 (2018).

13. A.D. Anggono, B. Sugito, A. Hariyanto, S. Subroto, S. Sarjito, Mechanical Behaviour Investigation of Aluminium Alloy Tailor Welded Blank Developed by Using Friction Stir Welding Technique, vol 914, Institute of Physics Publishing, (2017).

14. A.S. Baskoro, A.A.D. Nugroho, D. Rahayu, Suwarsono, G. Kiswanto, W. Winarto, Effects of welding parameters in micro friction stir lap welding of aluminum A1100, Advanced Material Research 789, 356-359 (2013).

15. F. Zarghani, S.M. Mousavizade, H.R. Ezatpour, G.R. Ebrahimi, Vacuum 147, 172-186 (2018).

16. Y. Zhao, H. Liu, T. Yang, Z. Lin, Y. Hu, International Journal of Advanced Manufacturing Technology 83, 1467-1475 (2016).

17. A. Garg, A. Bhattacharya, Materials and Design 127, 272-286 (2017)

18. A.S. Baskoro, Suwarsono, G. Kiswanto, Winarto, Effects of high speed tool rotation in micro friction stir spot welding of Aluminum A1100, Applied Mechanics and Materials 493, 739-742 (2014).

19. D.-A. Wang, C.-W. Chao, P.-C. Lin, J.-Y. Uan, Journal of Materials Processing Technology 210, 1942-1948 (2010).

20. T.P. Saju, R. Ganesh Narayanan, International Journal of Advanced Manufacturing Technology 95, 1377-1397 (2018). 